\title{
The Effects of Fiber Surface Modification and Thermal Aging on Composite Toughness and Its Measurement
}

Kenneth J. Bowles

Lewis Research Center

Cleveland, Ohio

Madhu Madhukar

University of Tennessee

Knoxville, Tennessee

Demetrios S. Papadopolous

Case Western Reserve University

Cleveland, Ohio

Linda Inghram and Linda McCorkle

Gilcrest Corporation

Cleveland, Ohio

Prepared for the

40th International Symposium and Exhibition

sponsored by the Society for the Advancement of Material and Process Engineering Anaheim, California, May 8-11, 1995 


\title{
THE EFFECTS OF FIBER SURFACE MODIFICATION AND THERMAL AGING ON COMPOSITE TOUGHNESS AND ITS MEASUREMENT
}

\author{
Kenneth J. Bowles \\ National Aeronautics and Space Administration \\ Lewis Research Center \\ Cleveland, Ohio 44135 \\ Madhu Madhukar \\ University of Tennessee at Knoxville \\ Knoxville, Tennessee 37996 \\ Demetrios S. Papadopolous \\ Case Western Reserve University \\ Cleveland, Ohio 44106 \\ Linda Inghram and Linda McCorkle \\ Gilcrest Corporation \\ Cleveland, Ohio 44135
}

\begin{abstract}
SUMMARY
A detailed experimental study was conducted to establish the structure-property relationships between elevated temperature aging and (1) fiber-matrix bonding, (2) Mode II interlaminar fracture toughness, and (3) failure modes of carbon fiber/PMR-15 composites. The fiber-matrix adhesion was varied by using carbon fibers with different surface treatments. Short beam shear tests were used to quantify the interfacial shear strength afforded by the use of the different fiber surface treatments.

The results of the short beam shear tests definitely showed that, for aging times up to $1000 \mathrm{hr}$, the aging process caused no observable changes in the bulk of the three composite materials that would degrade the shear properties of the material. Comparisons between the interlaminar shear strengths (ILSS) measured by the short beam shear tests and the $\mathrm{G}_{\mathrm{IIC}}$ test results, as measured by the ENF test, indicated that the differ-ences in the surface treatments significantly affected the fracture properties while the effect of the aging pro-cess was probably limited to changes at the starter crack tip. The fracture properties changed due to a shift in the fracture from an interfacial failure to a failure within the matrix when the fiber was changed from AU-4 to AS-4 or AS-4G.

There appears to be an effect of the fiber/matrix bonding on the thermo-oxidative stability of the composites that were tested. The low bonding afforded by the AU-4 fiber resulted in weight losses about twice those experienced by the AS-4 reinforced composites, the ones with the best TOS.
\end{abstract}

\section{INTRODUCTION}

During the past two decades, the commercial availability of the polyimide resin, PMR-15, has made it possible to design and fabricate carbon fiber reinforced composite structures that can sustain temperatures as high as $316^{\circ} \mathrm{C}$ for extended periods of time. This is about twice the temperature limit of commonly used epoxy composite materials.

Also, during the past decade, a significant amount of work has been conducted to quantify the extent of degradation and to comprehend the mechanisms involved in the degradation of the PMR-15 polyimide neat resin and carbon fiber composites (refs. 1 to 8). Microscopic examination of neat resin specimens, aged for various times at elevated temperatures, figure 1, revealed that polymer degradation occurred inside of a thin surface layer that progressively advanced inward toward the center of the specimen (ref. 8). Evidence indicated that the central portion of 
the specimen remained unchanged.From these observations it was concluded that com-posite aging damage was probably confined to the composite surface layer.

The thermal-oxidative degradation data suggest that the mechanism(s) involved in the mechanical properties changes observed in aged carbon fiber reinforced composites are probably initiated in the outer surface layers that are formed during the aging. Therefore, properties which are influenced by the fiber/matrix composition of the surface should show more change due to the aging process, than those properties which reflect properties of the central, protected sections of the composite materials.

Described herein are the results of a study which was designed to establish relationships between the Mode II fracture toughness failure modes, as measured with the End Notched Flexural (ENF) specimen, of a highly crosslinked polyimide matrix and identical carbon fiber reinforcements with three different surface treatments. The surface treatments provided three different levels of fiber-matrix adhesion. The testing was conducted after various aging times at $316^{\circ} \mathrm{C}$. The results are compared with short beam interlaminar shear strength (ILSS) test results of the same materials.

\section{MATERIALS}

The materials used in this study were the polyimide matrix polymer PMR-15 and three Hercules A-carbon fibers, AU-4, AS-4, and AS-4G. The AU-4 fiber has an untreated surface with a minimum of active sites on the surface. The AS-4 fiber was treated to introduce active sites on the fiber surface. The third carbon fiber, AS-4G, was surface treated and then the surfaces were coated with a water soluble, epoxy-compatible sizing referred to as the G-sizing. The fiber-matrix shear strength of the unaged materials were asssumed to be cor-related to the interlaminar shear strength (ILSS). Such correlation has been shown for graphite/epoxy com-posites (ref. 9). The ILSS data in this study suggest that the interfacial shear strengths of AS-4/PMR-15 and AS-4G/PMR-15 are higher than that of the AU-4/PMR-15 composite by about 60 and 74 percent respectively.

The three different types of fibers have been shown to produce three different strengths of interfacial bonding, as reflected in composite mechanical propertries (refs. 9 and 10). Possible reasons for these differences are attributed to surface roughness variances, percent Weighted Dipole Moment (WDM), and percent polar energy (ref. 11). Investigators at the University of Akron have shown by the use of Atomic Force Microscopy (AFM), that the A-type carbon fibers, produced by Hercules, have relatively smooth surfaces in relation to the surfaces of the G-type (BASF) and T-type (Amoco) fibers (ref. 11). Two observations were made. The first is that there are no topographical differences between the untreated and surface treated A-type carbon fiber surfaces. The second observation was that the grain size of each of the three fibers was in the range of 20 to $100 \mathrm{~nm}$ and elongated in the fiber axial direction. This indicates that the oxidative surface treatment that was used did not cause physical changes in the A-fiber surface, and the mechanical interlocking of the fiber with the matrix is not the primary promoter of interfacial bonding.

In another study (12), it was determined that dipole interactions between the polar groups on the fiber surfaces and those along the PMR-15 backbone play an important role in the fiber-matrix bonding. In addition, the high degree of bonding promoted by the large concentrations of surface dipole moeities allow the achieve-ment of extended retention of composite mechanical properties during thermo-oxdative exposure. The results of these two studies indicate that the chemical makeup of polar groups on the surfaces of the A-type carbon fibers promotes the differences in the mechanical and thermo-oxidative behavior of the composites made from these reinforcements.

A 50 percent by weight of monomeric solution in methanol was used to impregnate the wound fibers. The monomer solution was prepared at room temperature by the addition of the three monomers in a 2 monomethyl ester of 5-norbornene-2, 3- dicarboxylic acid: 3.0874 4' methylene dianiline: $2.0873,3$ ', 4,4'-benzophenonetetracarboxylic dianhydride stoichiometric ratio with enough methanol to make a $50 \mathrm{wt} \%$ solution.

The prepreg material was made by filament winding the fiber at 3.5 turns $/ \mathrm{cm} .(9$ turns/inch) for all three fibers. The prepreg was then cut into 10.2 by $10.2 \mathrm{~cm}$.(4 by 4 inch) squares and stacked into panels containing 24 unidirectional plies and two pieces of Kapton film across one end and positioned perpendicular to the fiber direction. These stacks were then cured under pressure for two hours at $316^{\circ} \mathrm{C}$ in a matched metal die mold in a heated press 
after imidizing the stack of plies under a light pressure at $204{ }^{\circ} \mathrm{C}$ for one hour. The average cured thickness of the plates was $0.71 \mathrm{~cm}$. $\left(0.28 \mathrm{in}\right.$.) The laminate plates were then given a $16 \mathrm{hr}$ standing postcure in air at $316^{\circ} \mathrm{C}$.

After postcure, the laminates were inspected by through-the-thickness $\mathrm{C}$-scan to check for blisters and the proper positioning of the Kapton inserts. Laminate plates which contained processing defects were rejected and replaced.

\section{EXPERIMENTAL PROCEDURES}

The specimen aging was done at $316^{\circ} \mathrm{C}$ in an air circulating oven. The plates were positioned vertically with the air flow across the two larger, flat surfaces. The air flow rate was $100 \mathrm{~cm} 3 / \mathrm{min}$. The plates were periodically removed, placed in a desiccator, allowed to cool to room temperature, and weighed on an analytical balance. After the weighing was completed, the plates were visually examined, and again placed within the ovens.

After the aging was completed, they were cut into test specimens with a water cooled, diamond wheel. Each plate was cut into four strips about 2.54 by $10.2 \mathrm{~cm}$. ( 1 by $4 \mathrm{in}$.) with the $10.2 \mathrm{~cm}$. (4 in.) direction parallel to the direction of the fibers. Prior to this operation, the plate edges were trimmed of $0.32 \mathrm{~cm}$. (0.125 in.) of edge material. A schematic of the specimen layout in the fabricated panel is shown in figure 2 .

The Mode II fracture testing was done using the End Notched Flexural (ENF) test method (ref. 9). The dimensions and geometry of the ENF specimen are shown in figure 3. Each specimen was built up of 24 unidirectional plies and contained a starter crack produced by two pieces of $0.0043 \mathrm{~cm}$. (0.0018 in) Kapton film. Two pieces were used to reduce the surface friction in the starter crack. The films were positioned in the midplane along one end of the plate and perpendicular to the orientation of the fibers. Figure 4 shows a photomicrograph of a specimen prior to testing. The two pieces of film and the effect of the films on the fiber orientation are readily evident in the picture.

A schematic of the ENF test specimen in the fixture is shown in figure 3. It is merely a three point flexure test with midpoint loading. The tests were run on an Instron 4505 load frame using the Series IX soft-ware to control the test and record the data. The midpoint deflection was monitored by means of crosshead displacement only. Four specimens were tested at the laboratory ambient temperature and humidity for each fiber and at each aging condition. The crosshead speed was $0.025 \mathrm{~cm} . /$ minute $(0.01 \mathrm{in} . / \mathrm{min})$. The load and support rollers for the fixture were sized according to ASTM D790. The test span was $8.89 \mathrm{~cm}$. $(3.5 \mathrm{in})$ which produced a span to depth ratio of 12.5 .

The digestion of the composite specimens to measure the fiber content was done as detailed in ASTM-D 3171 and reference 13.

Specimen density measurements were made using the immersion technique as specified in ASTM 792. The liquid was distilled water.

Interlaminar shear measurements were done in accordance with ASTM-D 2344. A span to depth ratio of 5 was used.

Glass transition temperatures, $\mathrm{T}_{\mathrm{G}}$ 's, were measured by Dynamic Mechanical Analysis (DMA) in air using a Rheometrics Mechanical Spectrometer/Dynamic Spectrometer RMS-800/RDS 11. The temperature ramp rate was $5{ }^{\circ} \mathrm{C}$ per min and the strain was 0.5 percent.

\section{RESULTS AND DISCUSSION}

\section{Thermo-Oxidative Stability Results}

The degradation of the three types of composites was monitored by changes in the physical and mechanical states of the test material. Points of concern physically were the weight changes, optical observation of thermally induced damage growth, and fracture surface morphology changes. Fracture toughness degradation and flexural modulus were the mechanical focal points that were tracked for thermal response. 
The weight loss data from the aging of the unmachined ENF specimen plates are presented in Table I. Four plates were made using each type of fiber. Three of these plates were aged at $316^{\circ} \mathrm{C}$ for 240,500 , and $1000 \mathrm{hr}$. They are designated in the table by a, b, and c respectively. The fourth was tested in the unaged condition. The plates that were aged for 1000 hours were also removed from the oven and weighed at 240 and 500 hours. The $500 \mathrm{hr}$ plate was also weighed after 240 hours of aging. The large weight loss value for the AU-4c plate at $1000 \mathrm{hr}$ is due to the extra surface area produced by the cracking that occurred at the plate ends that were oriented perpendicular to the fiber direction. Cracking was noted on this one plate, AU-4c, after $500 \mathrm{hr}$, but not on the end surfaces of AU-4b. The end of plate AU-4c is shown in figure 5. It may be that the cracking was just starting to occur at $500 \mathrm{hr}$, therefore, the effect of the newly forming crack surface area would be insignificant at this time.

Weight loss rate data is presented in figure 6 . The order of thermo-oxidative stability of the three composites, with the most stable first is AS-4, AS-4G, and then AU-4. It appears that interfacial bonding and surface sizing play an important part in elevated temperature composite degradation. The differences between the AS-4 and AS-4G data may be due to the rapid degradation of the low temperature epoxy sizing at the specimen surfaces where the oxygen is present.

The data in Figure 6 show similar behavior of the three different materials up to $500 \mathrm{hr}$ of aging. The weight loss rates increase significantly at $240 \mathrm{hr}$ of aging. This is most likely due to the release of reaction products that have not diffused from the composites during curing and postcuring. Then the rates decrease until the aging time reaches 500 hours. During this time, a degradation layer is forming and the interface between the layer and the unoxidized central material is advancing inward (ref. 8). During the time interval from $500 \mathrm{hr}$ until $1000 \mathrm{hr}$, the AS-4 and AS-4G reinforced composites lose weight at a steady rate while the weight loss rate increases for the AU-4 fiber reinforced composite. The steady rate indicates that the inward rate of move-ment of the interface and the composite surface inward movement due to the mass loss from the surface of the layer are about equal. Cracking of the edge surfaces of the AU-4 reinforced composite perpendicular to the direction of the fibers occurred beginning around the $500 \mathrm{hr}$ time. Its assumed that this cracking of the edges caused the increase in weight loss rate. The dashed line indicates the proposed weight loss rate for the AU-4 composite if the end cracking had not occurred. The difference between the dashed line and the measured data would be the weight loss rate from the crack surfaces.

\section{Mechanical Test Results}

The following describes the ENF specimen and the mathematical description of the mechanics involved in evaluating the results of the test. When a crack extension from an initial crack length of length a to a final length of $a+\delta a$ occurs in a linear elastic body, the Mode II strain energy release rate (SERR), $G_{I I}$, is given by:

$$
\mathrm{G}_{\mathrm{II}}=-(1 / \mathrm{W})(\mathrm{dU} / \mathrm{da})
$$

where $\mathrm{U}$ is the total strain energy stored in the specimen and $\mathrm{W}$ is the specimen width. The strain energy released during the crack extension (for a fixed grip case) is given by:

$$
\mathrm{U}=(1 / 2) \mathrm{Pu}-(1 / 2)(\mathrm{P}-\delta \mathrm{P})=(1 / 2) \mathrm{u} \delta \mathrm{P}
$$

where $\mathrm{P}$ and $\mathrm{u}$ are the applied load and displacement respectively.

The extension of the crack from a to $a+\delta a$ induces a change in the compliance of the beam. For a linear elastic body, the relationship between load and displacement is:

$$
\mathrm{u}=\mathrm{CP}
$$

where $\mathrm{C}$ is the compliance of the specimen. The crack extends when the value of $\mathrm{G}_{\mathrm{II}}$ reaches its critical value at the time when $\mathrm{P}=\mathrm{P}_{\mathrm{C}}$. Using equations (1) to (3): 


$$
\mathrm{G}_{\mathrm{IIC}}=\left(\mathrm{P}_{\mathrm{C}}{ }^{2 / 2 \mathrm{~W}}\right)(\mathrm{dC} / \mathrm{da})
$$

The $\mathrm{G}_{\text {IIC }}$ is referred to as Mode II fracture toughness.

The relationship between the compliance, $\mathrm{C}$, and the delamination length is (ref. 14):

$$
\mathrm{C}=\left(2 \mathrm{~L}^{3}+3 \mathrm{a}^{3}\right) /\left(8 \mathrm{E}_{1} \mathrm{Wh}^{3}\right)+(1.2 \mathrm{~L}+0.9 \mathrm{a}) /\left(4 \mathrm{WhG}_{13}\right)
$$

where $L$ is the half span, $h$ is the specimen half thickness and $E_{1}$ and $G_{13}$ are the flexural and interlaminar shear moduli, respectively. The first term in equation (5) is attributed to the bending component while the second term is due to the interlaminar shear component. By substitution, equation (4) becomes:

$$
\mathrm{G}_{\text {IIC }}=\left(9 \mathrm{a}^{2} \mathrm{P}_{\mathrm{C}^{2}}\right) /\left(16 \mathrm{E}_{1} \mathrm{~W}^{2} \mathrm{~h}^{3}\right)\left(1+0.2\left(\mathrm{E}_{1} / \mathrm{G}_{13}\right)(\mathrm{h} / \mathrm{a})^{2}\right)
$$

$\mathrm{E}_{1}$ and $\mathrm{G}_{13}$, the laminate Young's and shear moduli respectively, were calculated from the following equations (ref. 15):

$$
\mathrm{E}_{11}=\mathrm{k}_{\mathrm{f} 1} \mathrm{E}_{\mathrm{f} 1}+\mathrm{k}_{\mathrm{m}} \mathrm{E}_{\mathrm{m}}
$$

Where $\mathrm{k}_{\mathrm{f} 1}$ and $\mathrm{k}_{\mathrm{m}}$ are the volume fraction of the fiber and matrix respectively. $\mathrm{E}_{\mathrm{f} 1}$ is the Young's modulus of the fiber in the axis direction, and $E_{m}$ is the Young's modulus of the matrix. $E_{11}$ varies from $108.6 \mathrm{GPa}$ $(15.78 \mathrm{msi})$ at $50 \mathrm{v} / \mathrm{o}$ fiber to $129.6 \mathrm{GPa}(18.8 \mathrm{msi})$ at 60 v/o fiber.

$$
\mathrm{G}_{113}=\mathrm{G}_{\mathrm{m}} /\left(1-\mathrm{k}_{\mathrm{fl}} 0.5\left(1-\mathrm{G}_{\mathrm{m}} / \mathrm{G}_{\mathrm{f} 12}\right)\right)
$$

$\mathrm{G}_{\mathrm{m}}$ and $\mathrm{G}_{\mathrm{f} 12}$ are shear moduli of the resin and the fiber. Their values were taken as 1.22 and $13.8 \mathrm{GPa}\left(177.3 \times 10^{3}\right.$ and $2 \times 10^{6} \mathrm{lb} / \mathrm{in}^{2}$ ) respectively from reference 15 . The composite shear modulus varies from 4090 to $5263 \mathrm{MPa}$ (593 to $763 \mathrm{msi}$ ) for fiber loadings from 50 to 60 percent respectively.

Using calculated values for $E_{1}$ and $G_{13}$ respectively from equations (7) and (8), and 1.90 and $0.305 \mathrm{~cm}$. for a and $\mathrm{h}$ respectively, the shear term varies between 0.14 to. 13 for fiber volume fractions between 0.50 and 0.65 . The variation is about 1 percent which is insignificant over the range of fiber volumes that were studied. Substituting numerical values for $\mathrm{h}$ and a into equation (6) along with $2.4 \mathrm{~cm}$. (0.94 in.) for the width, W, we obtain:

$$
\mathrm{G}_{\mathrm{IIC}}=12.6 \times 10^{6}\left(\mathrm{P}_{\mathrm{C}}^{2 / \mathrm{E}_{11}}\right)\left(1+5.12 \times 10^{-3}\left(\mathrm{E}_{11} / \mathrm{G}_{13}\right)\right) \mathrm{mN} / \mathrm{m}^{2}
$$

or

$$
\mathrm{G}_{\mathrm{IIC}}=207.23\left(\mathrm{P}_{\mathrm{C}}^{2} / \mathrm{E}_{11}\right)\left(1+5.12 \times 10^{-3}\left(\mathrm{E}_{11} / \mathrm{G}_{13}\right) \text { in.lb./in }{ }^{2}\right.
$$

for specimens $2.4 \mathrm{~cm}$. (0.93 in.) wide.

It is common practice to remove all damaged edge surfaces before test specimens are machined. A strip of material, measuring $0.32 \mathrm{~cm}(0.125 \mathrm{in}$.) wide, was removed from each of the four sides of each plate to eliminate the damaged material. After leaving a $0.32 \mathrm{~cm}$. (0.125 in.) overhang at the support pins at each end of the ENF specimen, the final crack length became $1.90 \mathrm{~cm}(0.75 \mathrm{in}$.). This falls within the admissable 0.34 to $3.73 \mathrm{~cm}$. $(0.13$ to $1.5 \mathrm{in}$.) range calculated using the procedure recommended in reference 16.

Representative examples of the load-displacement curves for the twelve types of composites are shown in Figure 7. Unstable crack growth, indicated by a sudden drop in load after crack initiation, is evident for all the specimens that were tested. Unstable crack growth would be indicated by a stepwise decrease in load with time. The traces are characterized by a sharp drop in load at failure for all the AS-4 and AS- $4 \mathrm{G}$ reinforced specimens. The failure point is rounded in the traces of the load-deflection data of the AU-4 specimens. This indicates there was a failure 
process that took place over a finite period of time (stable crack initiation). This could be due to, fiber breakage, fiber pullout, or cracking at the fiber-matrix interface prior to the actual crack extension.

The load-displacement curves provided the data needed for the calculations of the maximum load, $\mathrm{P}_{\mathrm{C}}$, and the compliance, C. A summary of the mechanical test data that were acquired in this study is given in Table II. The results of the acid digestion and composite density measurements are given in Table II also along with the calculated void fractions for each plate that was treated and tested. The $\mathrm{G}_{\mathrm{II}}$ values are the averages of data from four specimens.

Equation (9) was used to calculate the $\mathrm{G}_{\mathrm{IIC}}$ values of the various specimens. The calculated average values of $\mathrm{G}_{\text {IIC }}$ (SERR) are listed for each of the twelve composites in Table II and presented graphically in figures 8 to 10. In relation to the fiber surface treatment affects, the $\mathrm{G}_{\text {IIC }}$ values show a very large increase in value when the surface is treated (AS-4 and S-4G) in comparison to those of the untreated (AU-4) fibers. The values are as high as seven times greater for the treated fibers. The aging appears to have very little effect on the AS- 4 and AS-4G composites during aging times up to $500 \mathrm{hr}$, but a significant effect for times between 500 and $1000 \mathrm{hr}$. The fracture toughness values For the AU-4 fiber reinforced composites are about the same magnitude as those measured for the graphite /epox composites reported in reference 9. The fracture tough-nesses for the composites with the AS-4 and AS-4G reinforcements are larger for the PMR-15 matrix material than for those with the epoxy matrix. Examination of the data shown in Tables III and IV should indicate that the only probable differences in mechanical properties of the constituent materials are those of the matrix polymers. The epoxy matrix used in the work of Reference 9 was EPON 828 (Shell Chemical Co.). The reasons for the difference can be explained by the interlaminar and in plane shear strength differences. The ILSS values reported in reference 10, are also presented in Table III. These values should be compared to the in plane shear data of references 10 and 17 in Table IV. The PMR-15 matrix composites possess inter-laminar shear strength values slightly higher than the values of the epoxy matrix composites. The Iosipescu values from reference 10 are also slightly lower than the Iosipescu strengths measured in Reference 17. Since the shear failure of the AU-4 composites is an interface failure and not a matrix failure, it might be assumed that the fracture toughness values for the two different composites (polyimide and epoxy) would be almost the same. If the polymer fracture toughnesses are compared, it is evident that the $\mathrm{G}_{\mathrm{IC}}$ value of the PMR-15 polymer is about twice that of the epoxy. The values are $230 \mathrm{~J} / \mathrm{m}^{2}$ for the polyimide (18) and $130 \mathrm{~J} / \mathrm{m}^{2}$ for the epoxy (ref. 9). Assuming that greater Mode I toughness signifies a greater Mode II toughness in comparing two polymers, the larger values of $\mathrm{G}_{\mathrm{IIC}}$ for the polyimide matrix composites are to be expected.

It appears that the fracture toughness of the AU-4 carbon reinforced specimens is not affected at all by the weight losses due to the aging at $316^{\circ} \mathrm{C}$. This is shown more graphically in Figure 11 where $\mathrm{G}_{\text {IIC }}$ is plotted as a function of composite weight loss. Statistically, the data from all four types of aged AU-4 specimens belong to the same population.

The cause for the decrease in the $\mathrm{G}_{\mathrm{IIC}}$ values of AS-4 and AS-4G composites with aging time can be better understood by comparing the Mode II fracture toughness with the results of in-plane shear tests, namely Iosipescu and ILSS, for the same type of composites. Both specimens are designed to promote failure at the thickness midplane. In Table III, the ILSS data for AU-4, AS-4, and AS-4G carbon fiber reinforced composites are listed at different aging times. Plates measuring 20.3 by $7.6 \mathrm{~cm}$. ( 8.0 by 3.0 in.) were aged for the required times and then the short beam shear specimens were machined from the plates. Thus, no ILSS specimen edges were directly exposed to the aging environment. In contrast, no edges of the ENF specimens were exposed to the oxidizing atmosphere, but the surfaces of the starter cracks were.

The results of in-plane Iosipescu tests on the same A-type fiber/PMR-15 composites (17) indicate no significant changes in either the shear moduli or strengths for any of the specimens during the aging process. These results and those of the ILSS tests are consistent with and support the other evidence which indicates that composite chemical changes are limited to the composite surface layers.

The data in Table III indicate that the aging process did not significantly affect the material at the midplane of the ILSS specimens. The AU-4 specimens did show a 25 percent reduction in the ILSS after $2405 \mathrm{hr}$ at $316^{\circ} \mathrm{C}$, but the reduction was insignificant at times up to 1084 hours. The reduction may be due to extensive surface damage which resulted in a large amount of exposed fibers on the surfaces. This would give false thickness readings. 
Except for the crack tip, the central material of the ENF specimens should remain unchanged, both chemically and mechanically, during the course of the aging periods. Of course they didn't retain initial mechanical property values. These data suggest that the changes in the values of the Mode II fracture toughness due to the effect of aging may be caused by oxidation at the crack tip. This means that internal delaminations that are completely isolated from the exterior elevated temperature environment will probably not grow in an accelerated manner due to the exposure of the structure to the environment.

\section{Microscopic Examination}

The fracture surfaces of representative specimens from the twelve groups of composites were examined by Scanning Electron Microscopy (SEM). The photomicrographs of these fracture surfaces are shown in figures 12 to 14. The AU-4/PMR-15 composites show almost entirely interfacial failure with the exposure of almost completely bare fiber surfaces along the fracture surface. The surfaces of the AS-4 and AS-4G composites show slightly different features. They do exhibit some interfacial failure, as evidenced by the bare fiber surfaces, but they also contain a lot of surface debris and wave like or lip and peak shear tears.

An improvement in the adhesion between the fiber and the matrix, such as seen in the AS- 4 composites as compared to the AU-4 reinforced composites, changes the failure mode from interfacial failure to a failure partially residing in the matrix. Matrix fracture involves the expenditure of more work than that involving an interfacial fracture along the surface of a carbon fiber with minimal active sites present along the surfaces. This is due to the available number of energy absorbing events that can occur, such as: matrix deformation, matrix cracking, fiber pullout, etc. When the interfacial strength approaches that of the matrix, the increase in interfacial bonding may not result in as great an increase in $\mathrm{G}_{\mathrm{IIC}}$ as was produced by changing from AU-4 to AS-4 reinforcement. The fracture morphology of the AU-4 composite specimen was found to be slightly different than those of the AS-4 and AS-4G specimens, and the surfaces of the AS- 4 and AS- $4 \mathrm{G}$ specimens appeared similar.

In the photomicrographs shown in figures 15 to 17, the crack tip areas of the unaged ENF specimens are compared with the those of the specimens that were aged for $1000 \mathrm{hr}$. It is evident that the failures at the crack tips of the unaged specimens are sharp and straight. The epoxy metallographic mount material has filled the cracks in these photos and may make examination a little more difficult because of this. The different materials are labeled and denoted by arrows. Signs of degradation of the neat resin wedge in front of the starter crack are visible only in the wedge in the $1000 \mathrm{hr}$ AU-4 specimen shown in figure 15. Voids are also observed in the resin rich areas in the vicinity of the wedge. This indicates that the oxidizing atmosphere had penetrated to the crack tip. Voids were also observed in photomicrographs of AU-4 specimens aged for 240 and $500 \mathrm{hr}$ at $316^{\circ} \mathrm{C}$. The aged AS-4 and AS-4G specimens in figures 16 and 17 do not contain the round voids that are present in figure 15 . The large horizontal spaces between the ends of the films and the neat resin wedges suggest that a separation between the film and resin wedges may have occurred at this juncture during the aging process. Therefore, there would be no film-resin strain energy absorbed during failure since no cracking would take place at this interface during testing. In effect, this would have increased the starter crack length. This possibility was not considered in selecting the dimensions used in the calculations of the $\mathrm{G}_{\mathrm{IIC}}$ values presented herein. The slight increase in the value of the crack length,a, as indicated in equation (6), would increase the fracture toughness value, but only slightly from the dimensions that are involved. This would not be of significant contribution to the cause for the greater $\mathrm{G}_{\mathrm{IIC}}$ for the polyimide composiytes than for the epoxy laminates.

An AU-4 fiber reinforced composite plate was aged in the oven at $316^{\circ} \mathrm{C}$ for $1000 \mathrm{hr}$. At times of 0,240 , 500 , and $1000 \mathrm{hr}$ a strip of the plate was cut from the plate and retained for microscopic examination. These specimens were not subjected to mechanical testing. After the strips were removed the plate was returned to the oven for further aging. Figures 18 (a) and (b) show the progression of degradation at the crack tip as the aging time reached $1000 \mathrm{hr}$. These pictures clearly show that an extensive amount of degradation occurs in the matrix at the crack tip as the aging process continues. These pictures confirm that the voids observed in figure 15 are real and also that they are caused by the oxidative aging of the AU-4/PMR-15 composite material.

A significantly different behavior of the AU fiber reinforced ENF specimens was noted after tests were conducted and the specimens were cut. They were cut one inch past the end of the starter crack to allow examination 
of the newly formed crack surfaces. The two pieces of the specimens reinforced with AS-4 and AS-4G fell apart when the cut was made. There was no evidence of any bonding between the surfaces of the extended cracks. In contrast, the specimens that were reinforced with AU-4 fibers had to be separated by prying them apart. The reason for this difficulty in separating the two pieces of the tested AU-4 reinforced composites is apparent in figures 15 to 17 . The widths of the extended cracks are greater for the AS-4 and AS-4G specimens than for the AU-4 specimens. The cracks in the AU-4 specimens are barely visible. This is probably due to the magnitude of the load at failure. The lighter load results in a smaller flexural displacement and smaller relative displacements between adjoining fibers that are positioned on opposite sides of the new crack.

$\underline{\mathrm{T}}_{\mathrm{G}}$ Measurement-The $\mathrm{T}_{\mathrm{G}}$ 's of the three materials at different aging times are presented in Table II. It is evident that there are no significant differences in $\mathrm{T}_{\mathrm{G}}$ 's at any of the times that were studied.The $\mathrm{T}_{\mathrm{G}}$ 's for all three materials increase with agingh time.

\section{SUMMARY AND CONCLUSIONS}

A detailed experimental study was conducted to establish the structure-property relationships between elevated temperature aging and (1) fiber-matrix bonding, (2) Mode II interlaminar fracture toughness, and (3) failure modes of carbon fiber/PMR-15 composites. The fiber-matrix adhesion was varied by using carbon fibers with different surface treatments. Short beam shear tests were used to quantify the interfacial shear strength afforded by the use of the different fiber surface treatments.

The results of the short beam shear tests definitely showed that, for aging times up to 1000 hours, the aging process caused no observable changes in the bulk of the three composite materials that would degrade the shear properties of the material. This indicates that the mechanical properties that are degraded by extended elevated temperature aging are those that are sensitive to composite surface changes and thickness reductions due to surface degradation. Comparisons between the interlaminar shear strengths (ILSS) measured by the short beam shear tests and the $\mathrm{G}_{\mathrm{IIC}}$ test results, as measured by the ENF test, indicated that the differences in the surface treatments significantly affected the fracture proprties while the effect of the aging process was probably limited to changes at the starter crack tip. The fracture properties changed due to a shift in the fracture from an interfacial failure to a failure within the matrix when the fiber was changed from AU-4 to AS-4 or AS-4G. The failure surface topography indicates that some plastic deformation took place in the Mode II fracture process.

The only changes in the neat resin wedge at the pre-crack tip of the AU-4 ENF specimen involved the type of degradation previously observed in large specimens of neat resin PMR-15. Voids and cracks were not found in the small wedges of matrix material that were formed in the precracks in the AS-4 and AS-4G specimens. The initiation of the crack extension actually involved the separation of the composite from the neat resin wedge surface and not an interlaminar delamination. The observations that were made in this investigation obviously do not pertain to delaminations that are not directly exposed to the damaging environment. From the ILSS results, it is expected that under these circumstances, no degradation of fracture toughness would occur due to thermal aging.

There appears to be an effect of the fiber/matrix bonding on the thermo-oxidative stability of the composites that were tested. The low bonding afforded by the AU-4 fiber resulted in weight losses about twice those experienced by the AS-4 reinforced composites, the ones with the best TOS. In addition, the ends of the specimens with the AU-4 fibers began developing cracks parallel to the fibers after 500 hours of aging. The neat resin wedges at the ends of the crack tips of the aged AU-4 specimens contain voids like those in figure 1 . The AS-4G composites had better TOS than the AU-4 specimens, but somewhat worse TOS than the AS-4 composite specimens. This was probably due to the presence of 1.5 percent epoxy sizing at the fiber/matrix interface. The low temperature epoxy sizing probably degraded fast at the surfaces allowing rapid penetration of the air through the interfaces.

When the TOS data are presented in terms of weight per hour and surface area, the weight loss rate appears to be constant after an initial transition period which was about 500 hours in this study. The onset of destructive occurrences, such as crack formation and other new surface forming events, can be observed as an increase in the rate of weight loss with time. This type of data monitoring should be investigated further to see if it can be utilized in defining the mechanisms that can be used to model long term environmental exposure of polymer matrix composites. 


\section{REFERENCES}

1. K.J. Bowles and A. Meyers, "Specimen Geometry Effects on Graphite/PMR-15 Composites During ThermoOxidative Aging", 31st International SAMPE Symposium and Exhibition (1986) 1285.

2. K.J.Bowles and G. Nowak, Journal of Composite Materials, (1988) 966.

3. K.J.Bowles, SAMPE Quarterly, 21, 4 (1990) 6.

4. F.J. Magendie, "Thermal Stability of Ceramic and Carbon Fiber Reinforced Bismaleimide Matrix Composites", Master's Thesis, Department of Chemical Engineering, University of Washington, Seattle, WA,1990.

5 . J.D. Nam and J.C. Sefertis, SAMPE Quarterly, 24, 1, (1992) 10.

6. K.J. Bowles, D. Jayne, and T.A. Leonhardt, SAMPE Quarterly, 24, 2, (1993) 2.

7. K.J. Bowles, D. Jayne, T.A. Leonhardt, and D. Bors, "Thermal Stability Relationships Between PMR-15 Resin and Its Composites", NASA TM-106285, (1993).

8. K.J. Bowles, SAMPE Quarterly, 24, 2, (1993) 49.

9. M.S. Madhukar and L.T. Drzal, Journal of Composite Materials, (1992)

10. M.S. Madhukar and L.T. Drzal, Journal of Composite Materials, Vol. 25, (1991) 932.

11. I. Jangchud, "Investigation of Carbon Fiber Surfaces Using Atomic Force Microscopy", Master Degree Thesis, University of Akron, December, 1992

12. A. M. Serrano, I. Jangchud, R. K. Eby, and K. J. Bowles, "High Temperature Polymer Matrix Composites", Proceedings of the 3rd Pacific Rim Forum on Composites, Nov. 2-4, 1993, Honolulu, Hawaii.

13.M.K. O'Rell, C.H. Sheppard, R.W. Vaughan, and R.J. Jones, "Development of Autoclavable Polyimides",

NASA CR-134716, TRW Redondo Beach, CA, Contract NAS3-17770 (1974).

14. L.A. Carlsson, J.W. Gillespie, and R.B. Pipes, Journal of Composite Materials, Vol. 20 (1986) 594.

15. P.L.N. Murthy and C.C. Chamis, "Integrated Composite Analyzer (ICAN)", NASA TP-2515, 1986.

16. R.B. Pipes, R.A. Blake, J.W. Gillespie, Jr., and L.A. Carlsson, Delaware Composites Design Encyclopedia,

Vol. 6- "Test Methods".

17. M. S. Madhukar, K. J. Bowles, Demetrios S. Papadopolous, and Linda McCorkle, "Thermo-Oxidative Stability of Graphite/PMR-15 Composites: Effect of Fiber Surface Modification on Composite Shear Properties", to be published.

18. W. D. Bascom, Naval Research Laboratory, March 1978 and Product Engineering, May 1978, page 43.

\begin{tabular}{|c|c|c|c|}
\hline Fiber & $\begin{array}{c}\text { Aging } \\
\text { time, } \\
\mathrm{hr}\end{array}$ & $\begin{array}{c}\text { Weight } \\
\text { loss, } \\
\text { Gms } \\
\end{array}$ & $\begin{array}{c}\text { Weight } \\
\text { loss, } \\
\text { percent }\end{array}$ \\
\hline AU-4a & 240 & 0.706 & 0.62 \\
\hline AU-4b & 240 & .8103 & .72 \\
\hline AU- $4 \mathrm{c}$ & 240 & .8901 & .79 \\
\hline $\mathrm{AU}-4 \mathrm{~b}$ & 500 & 1.1537 & 1.01 \\
\hline $\mathrm{AU}-4 \mathrm{c}$ & 500 & 1.3775 & 1.22 \\
\hline AU $-4 \mathrm{c}$ & 1000 & 3.9188 & 3.47 \\
\hline AS-4a & 240 & 0.3725 & 0.32 \\
\hline AS- $4 b$ & 240 & .4184 & .36 \\
\hline AS- $4 c$ & 240 & .4041 & .34 \\
\hline AS-4b & 500 & .5787 & .5 \\
\hline AS- $4 c$ & 500 & .6803 & .52 \\
\hline AS- $4 c$ & 1000 & 1.4018 & 1.19 \\
\hline AS- $4 \mathrm{Ga}$ & 240 & 0.6645 & 0.60 \\
\hline $\mathrm{AS}-4 \mathrm{~Gb}$ & 240 & .6574 & .55 \\
\hline AS-4Gc & 240 & .7088 & .62 \\
\hline AS- $4 \mathrm{~Gb}$ & 500 & .904 & .76 \\
\hline AS- $4 \mathrm{Gc}$ & 500 & .8847 & .77 \\
\hline AS-4Gc & 1000 & .725 & 1.5 \\
\hline
\end{tabular}


TABLE II.-MODE II FRACTURE TOUGHNESS AND OTHER PROPERTIES OF COMPOSITES

\begin{tabular}{|c|c|c|c|c|c|c|}
\hline Specimen & $\begin{array}{l}\text { Aging } \\
\text { time, } \\
\mathrm{hr}\end{array}$ & $\begin{array}{l}\text { Fiber content, } \\
\text { percent by volume }\end{array}$ & $\begin{array}{l}\text { Void content, } \\
\text { percent by vol- } \\
\text { ume }\end{array}$ & $\begin{array}{c}\text { Fracture toughness } \\
\mathrm{G}, \mathrm{Kj} / \mathrm{m}, \\
\text { in.lb/sq in. }\end{array}$ & $\begin{array}{l}\text { Flexuaral } \\
\text { modulus, } \\
\text { GPa, Msi }\end{array}$ & $\begin{array}{c}\text { Glass transition } \\
\text { temperature, } \\
{ }^{\circ} \mathrm{C}\end{array}$ \\
\hline $\begin{array}{l}\text { AU-4 } \\
\text { AU-4 } \\
\text { AU-4 } \\
\text { AU-4 }\end{array}$ & $\begin{array}{c}0 \\
240 \\
50 \\
1000\end{array}$ & $\begin{array}{l}51.0 \\
59.0 \\
57.6 \\
55.5\end{array}$ & $\begin{array}{l}0.0 \\
1.4 \\
0.0 \\
1.0\end{array}$ & $\begin{array}{l}0.42(2.4) \\
.40(2.26) \\
.44(2.53) \\
.33(1.86)\end{array}$ & $\begin{array}{c}66.2(9.6) \\
70.3(10.2) \\
73.1(10.6) \\
73.1(10.6)\end{array}$ & $\begin{array}{l}337 \\
344 \\
350 \\
362\end{array}$ \\
\hline $\begin{array}{l}\text { AS-4 } \\
\text { AS-4 } \\
\text { AS-4 } \\
\text { AS-4 }\end{array}$ & $\begin{array}{c}0 \\
240 \\
50 \\
1000\end{array}$ & $\begin{array}{l}57.8 \\
55.0 \\
60.4 \\
58.8\end{array}$ & $\begin{array}{l}0.2 \\
0.0 \\
0.0 \\
0.0\end{array}$ & $\begin{array}{l}2.73(15.56) \\
3.26(18.59) \\
2.04(11.64) \\
1.611(9.20)\end{array}$ & $\begin{array}{l}80.0(11.6) \\
77.2(11.2) \\
84.1(12.2) \\
77.9(11.3)\end{array}$ & $\begin{array}{l}345 \\
361 \\
379 \\
363\end{array}$ \\
\hline $\begin{array}{l}\text { AS- } 4 \mathrm{G} \\
\text { AS- } 4 \mathrm{G} \\
\text { AS- } 4 \mathrm{G} \\
\text { AS- } 4 \mathrm{G} \\
\end{array}$ & $\begin{array}{c}0 \\
240 \\
50 \\
1000 \\
\end{array}$ & $\begin{array}{l}56.7 \\
59.1 \\
55.0 \\
59.6 \\
\end{array}$ & $\begin{array}{r}.5 \\
.6 \\
1.1 \\
1.3 \\
\end{array}$ & $\begin{array}{c}2.37(13.52) \\
1.63(9.33) \\
2.16(12.33) \\
.70(3.99) \\
\end{array}$ & $\begin{array}{l}78.6(11.4) \\
78.6(11.4) \\
73.8(10.7) \\
71.0(10.3) \\
\end{array}$ & $\begin{array}{l}354 \\
343 \\
341 \\
360 \\
\end{array}$ \\
\hline
\end{tabular}

TABLE III.-INTERLAMINAR SHEAR STRENGTH FOR UNDIRECTIONAL COMPOSITES REINFORCED WITH DEFFERENT A-TYPE CARBON FIBERS ANDAGED AT $316^{\circ} \mathrm{C}$ FOR DIFFERENT TIMES

\begin{tabular}{|c|c|c|c|c|c|c|}
\hline $\begin{array}{c}\text { Time, } \\
\text { hrs }\end{array}$ & 0 & 72 & 144 & 552 & 696 & 1084 \\
\hline \multicolumn{7}{|c|}{ Interlaminar shear strength $\mathrm{MPa} /(\mathrm{Ksi})$} \\
\hline \multicolumn{7}{|c|}{ PMR-15 } \\
\hline $\begin{array}{c}\text { AU-4 } \\
\text { AS-4 } \\
\text { AS-4G } \\
\end{array}$ & $\begin{array}{c}55.7(8.1) \\
89.1(12.9) \\
96.9(14.1) \\
\end{array}$ & $\begin{array}{l}82.6(12.0) \\
82.6(12.0)\end{array}$ & $\begin{array}{l}87.4(12.7) \\
87.4(12.7)\end{array}$ & $\begin{array}{l}55.7(8.1) \\
93.8(13.6) \\
\end{array}$ & $85.4(12.4)$ & $\begin{array}{r}54.6(7.9) \\
88.5(12.8) \\
\end{array}$ \\
\hline \multicolumn{7}{|c|}{ Epoxy } \\
\hline $\begin{array}{c}\mathrm{AU}-4 \\
\mathrm{AS}-4 \\
\mathrm{AS}-4 \mathrm{G} \\
\end{array}$ & $\begin{array}{c}47.6(6.9) \\
84.1(12.2) \\
93.1(13.5) \\
\end{array}$ & - & - & --o- & - & -.-n- \\
\hline
\end{tabular}

TABLE IV.-IOSIPESCU SHEAR STRENGTHS OF PMR-15 AND EPOXY COMPOSITES

\begin{tabular}{|c|c|}
\hline Matrix/Fiber & $\begin{array}{c}\text { Shear strength, } \\
\text { MPa }\end{array}$ \\
\hline PMR-15/AU-4 & 78.4 \\
PMR-15/AS-4 & 113.0 \\
PMR-15/AS-4G & 97.8 \\
Epoxy/AU-4 & 55.0 \\
Epoxy/AS-4 & 95.6 \\
Epoxy/AS-4C & 93.8 \\
\hline
\end{tabular}




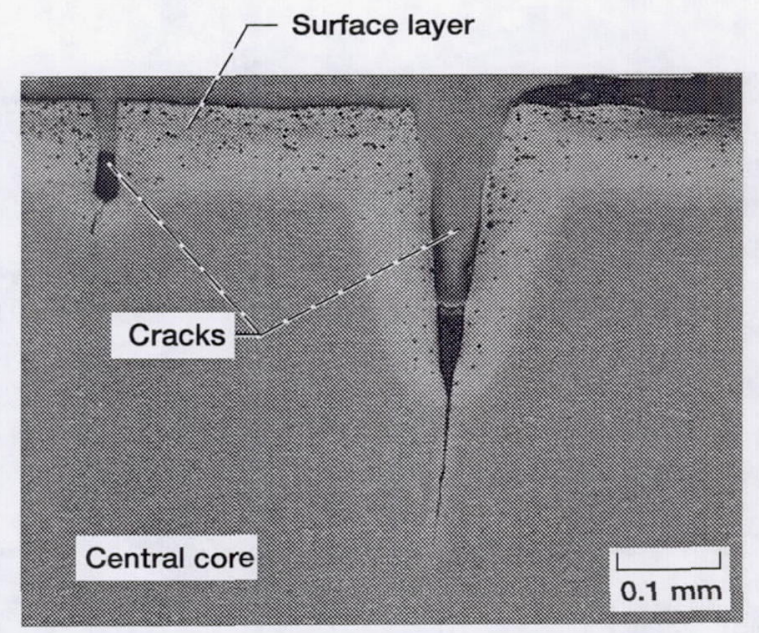

Figure 1.-Surface layer degradation in PMR-15 neat resin after aging in air at $343^{\circ} \mathrm{C}$ for $362 \mathrm{hr}$.

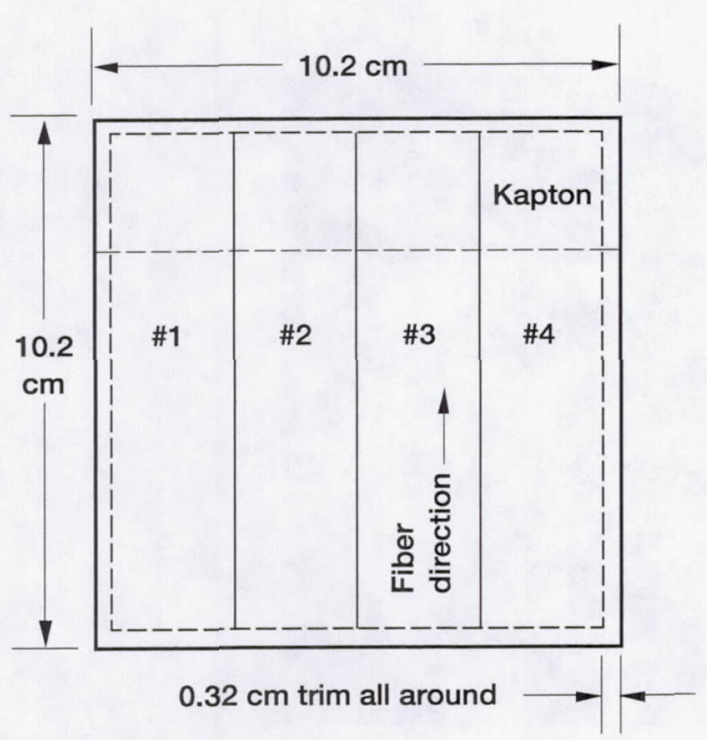

Figure 2.-Schematic of 24 ply ENF plate and specimen positions.
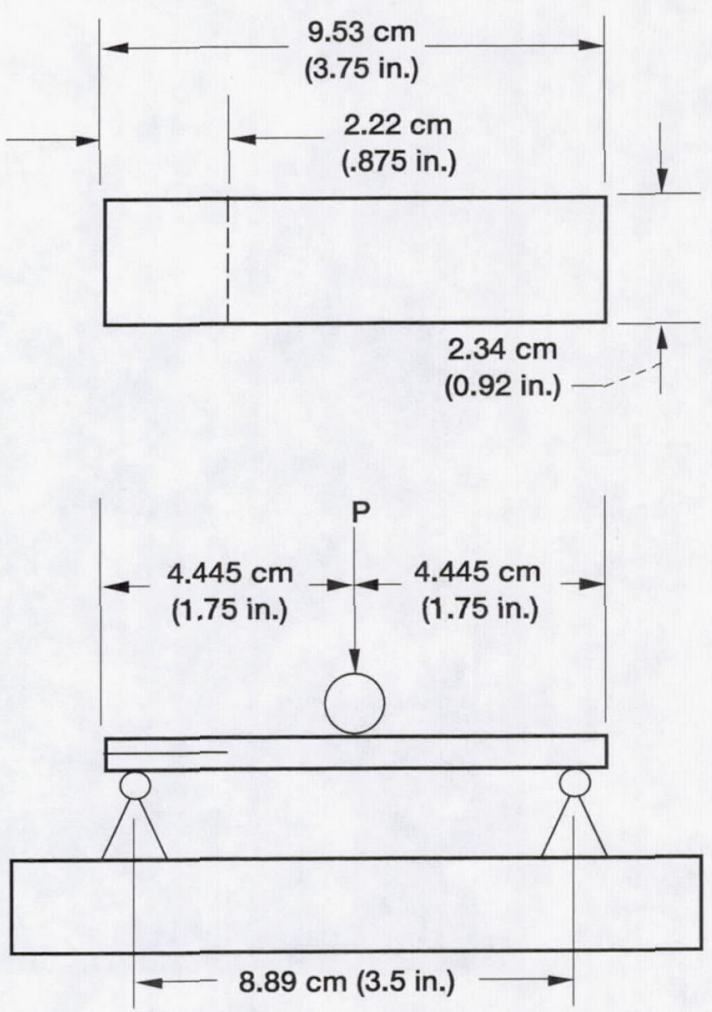

Figure 3.-Edge notch flexure fixture. 


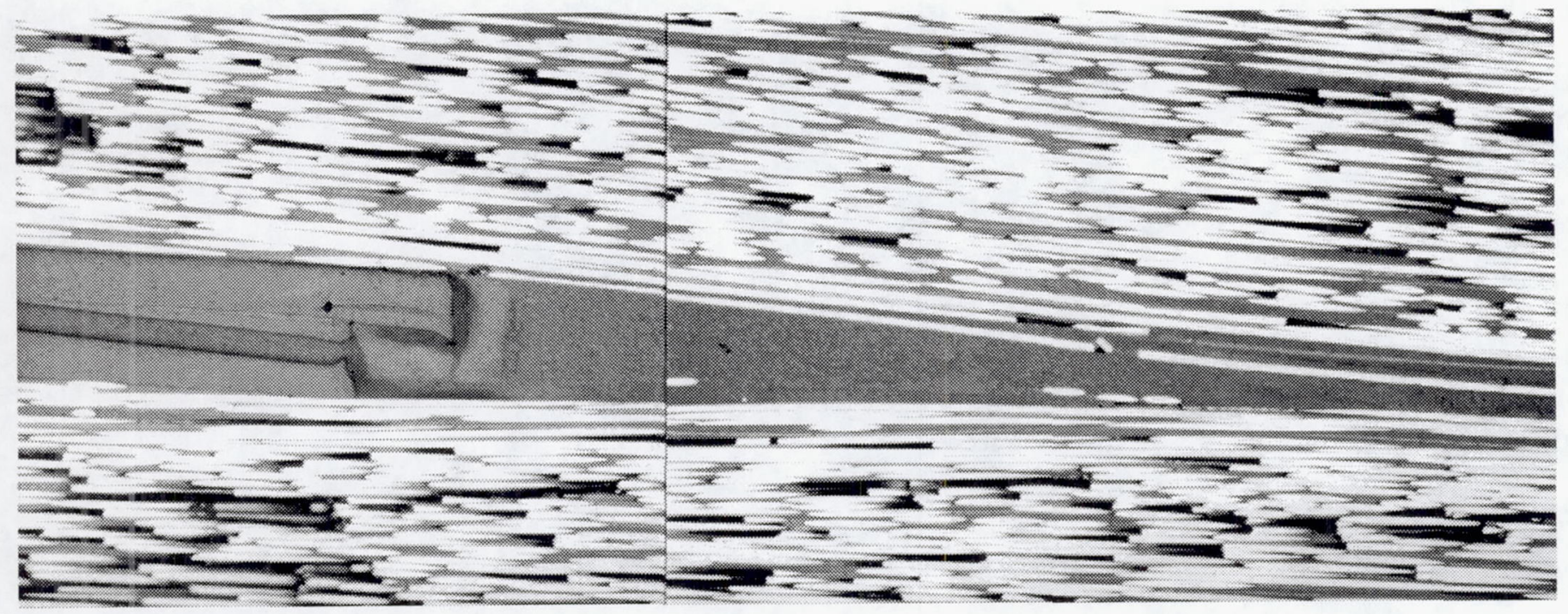

Figure 4.- Unaged AU-4/PMR-15 unidirectional composite. Solid wedge at right is neat resin material.

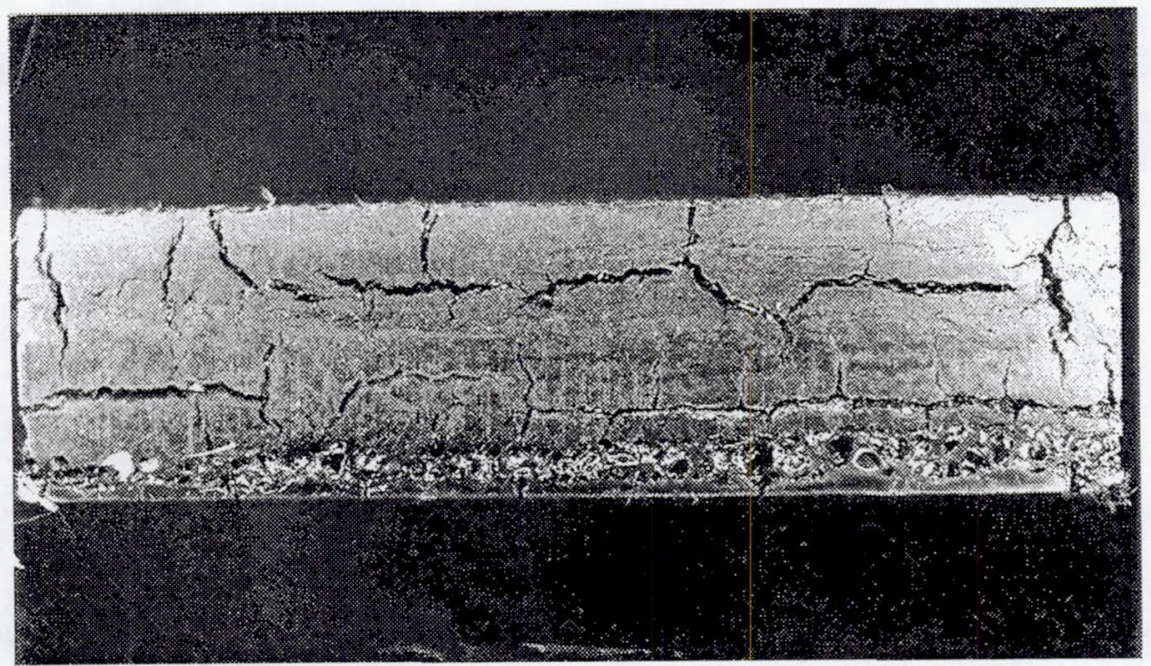

Figure 5.-Cracked end of AU-4 panel that was aged for $500 \mathrm{hr}$ at $316^{\circ} \mathrm{C}$. 


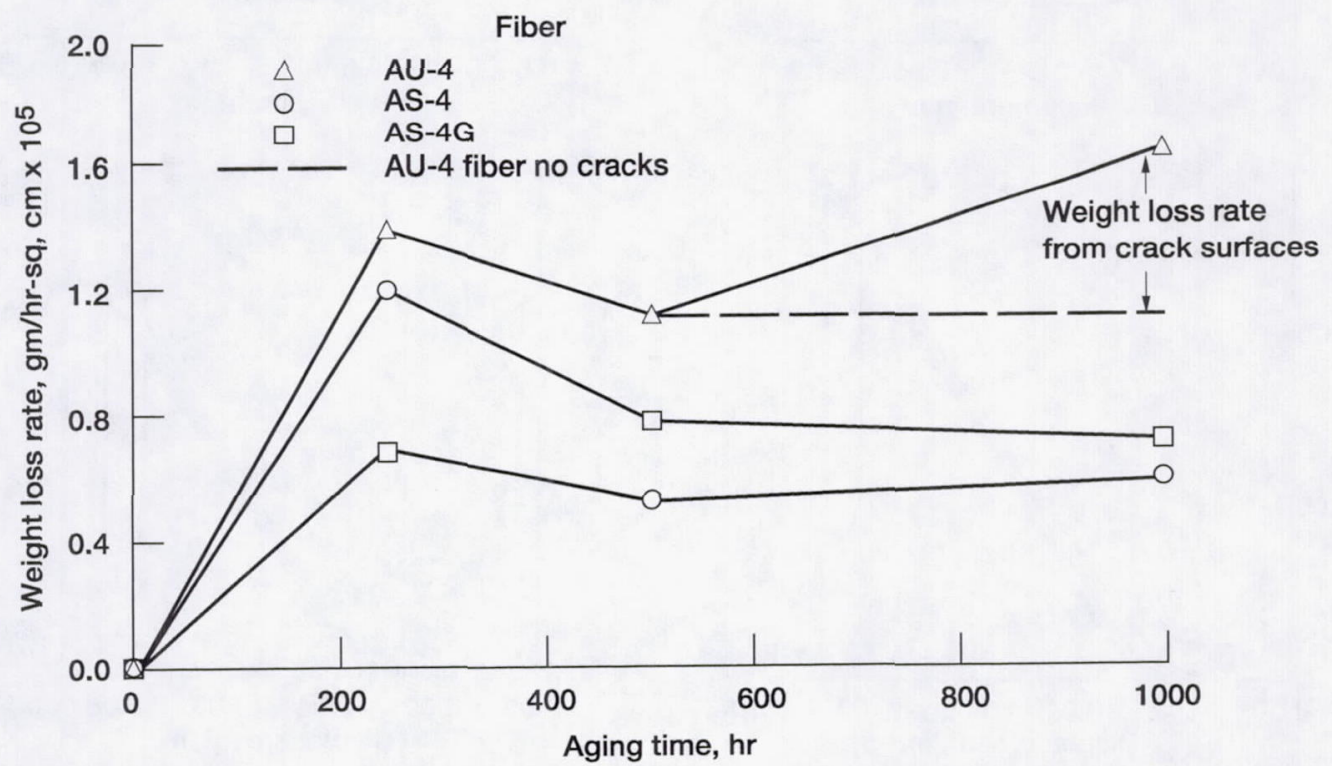

Figure 6.-Rate loss rates from ENF plates aged in air at $316^{\circ} \mathrm{C}$. 

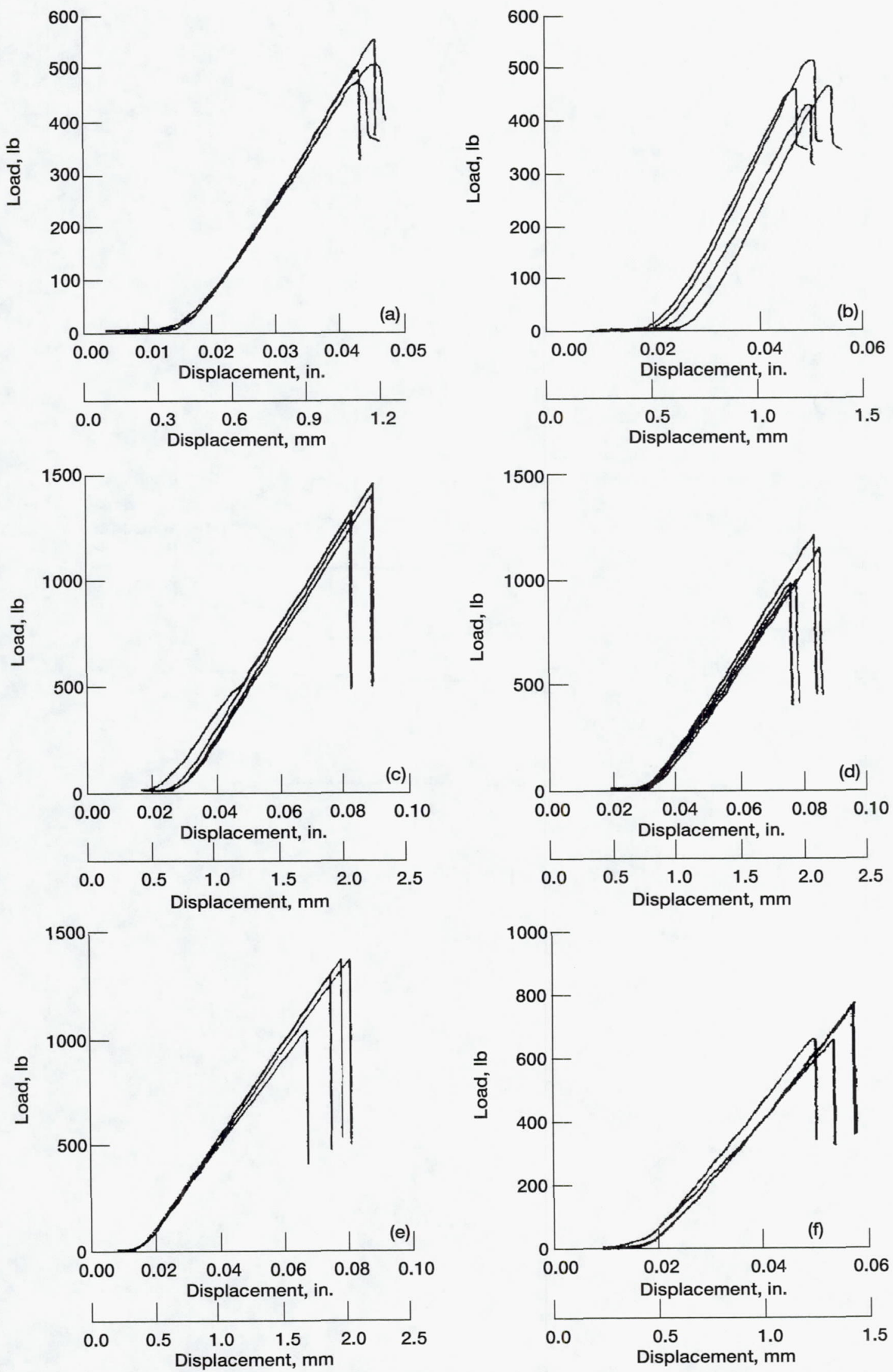

Figure 7.-Load extension curves for ENF tests. (a) AU-4 fiber no aging. (b) AU-4 fiber $1000 \mathrm{hr}$. (c) AS-4 fiber no aging. (d) AS-4G fiber no aging. (e) AS-4 fiber $1000 \mathrm{hr}$. (f) AS-4G fiber $1000 \mathrm{hr}$. 


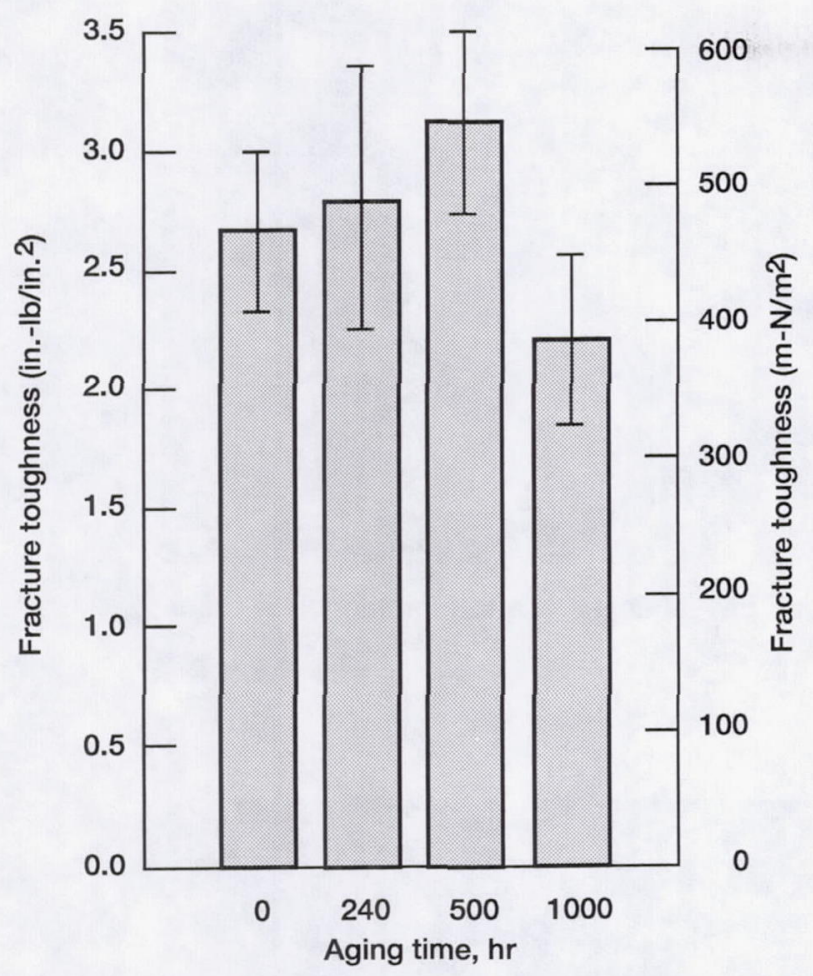

Figure 8.-Fracture toughness $\mathrm{G}_{\| \mathrm{c}}$ normalized to $60 \%$ fiber volume AU4/PMR-15.

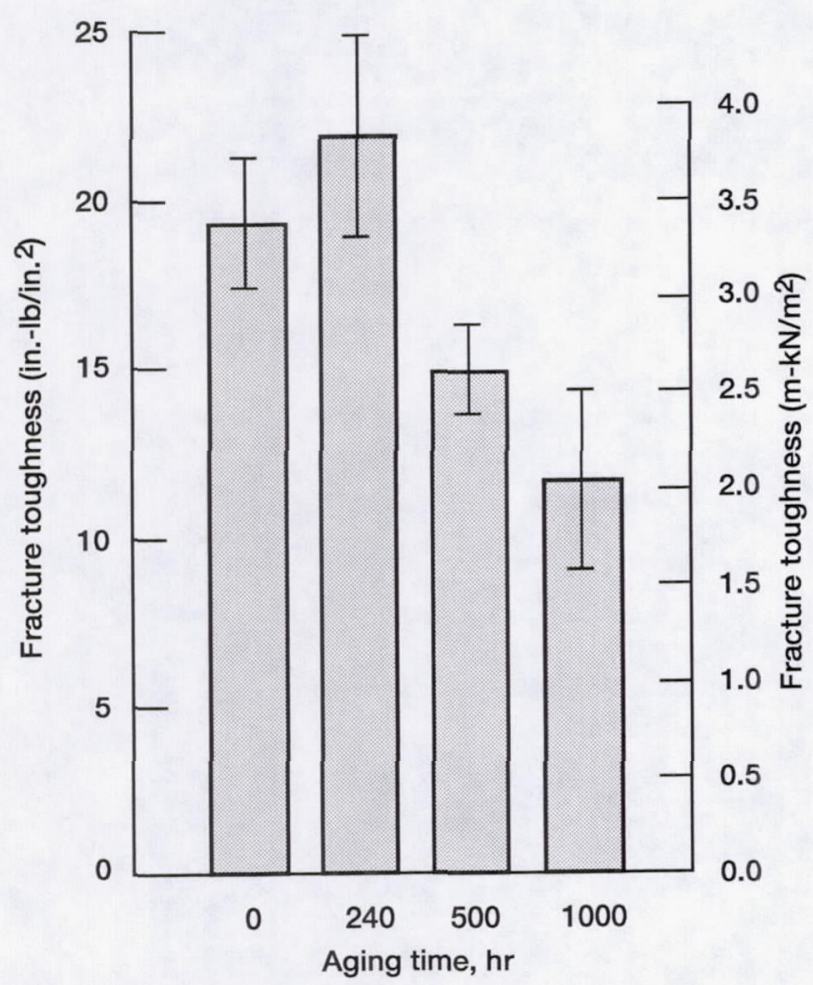

Figure 9-Fracture toughness $\mathrm{G}_{\| \mathrm{c}}$ normalized to $60 \%$ fiber volume AS4/PMR-15.

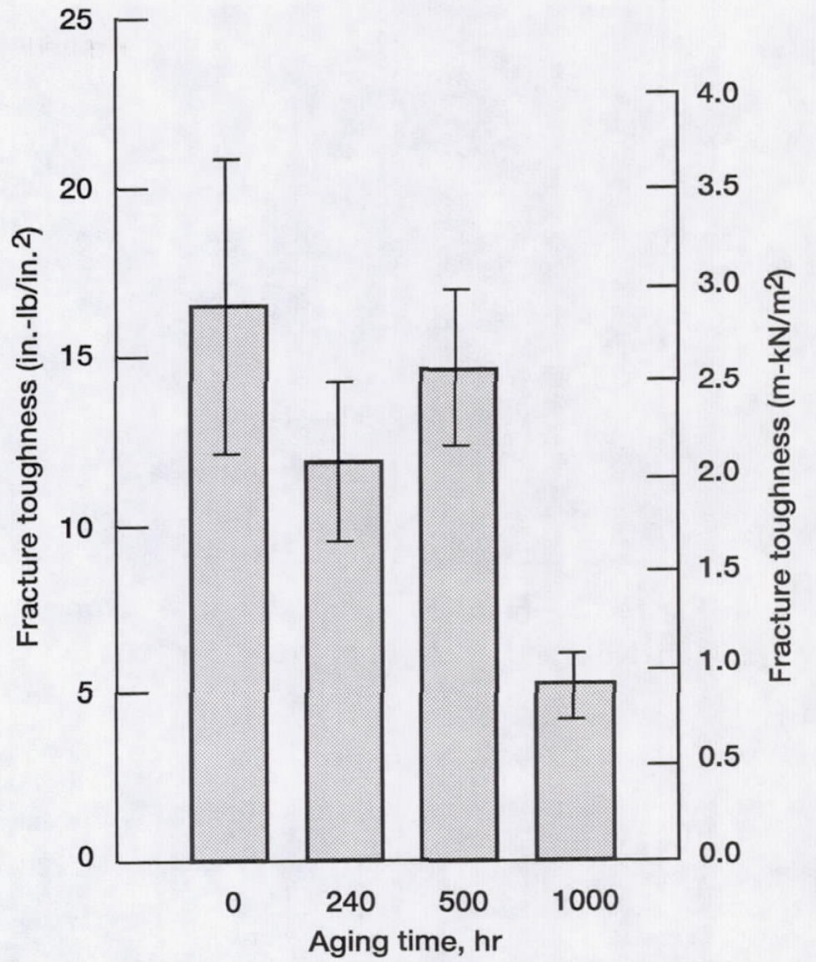

Figure 10.-Fracture toughness $\mathrm{G}_{\| \mathrm{c}}$ normalized to $60 \%$ fiber volume ASG4/PMR-15.

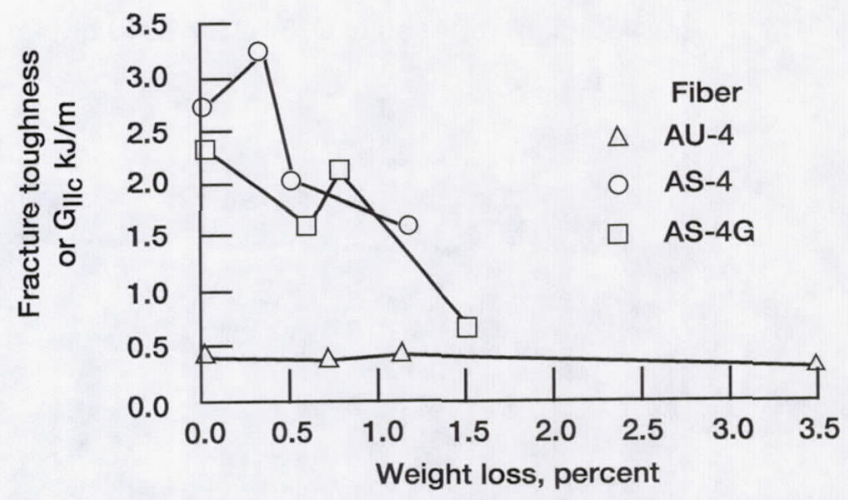

Figure 11.-Fracture toughness as a function of composite weight loss. 

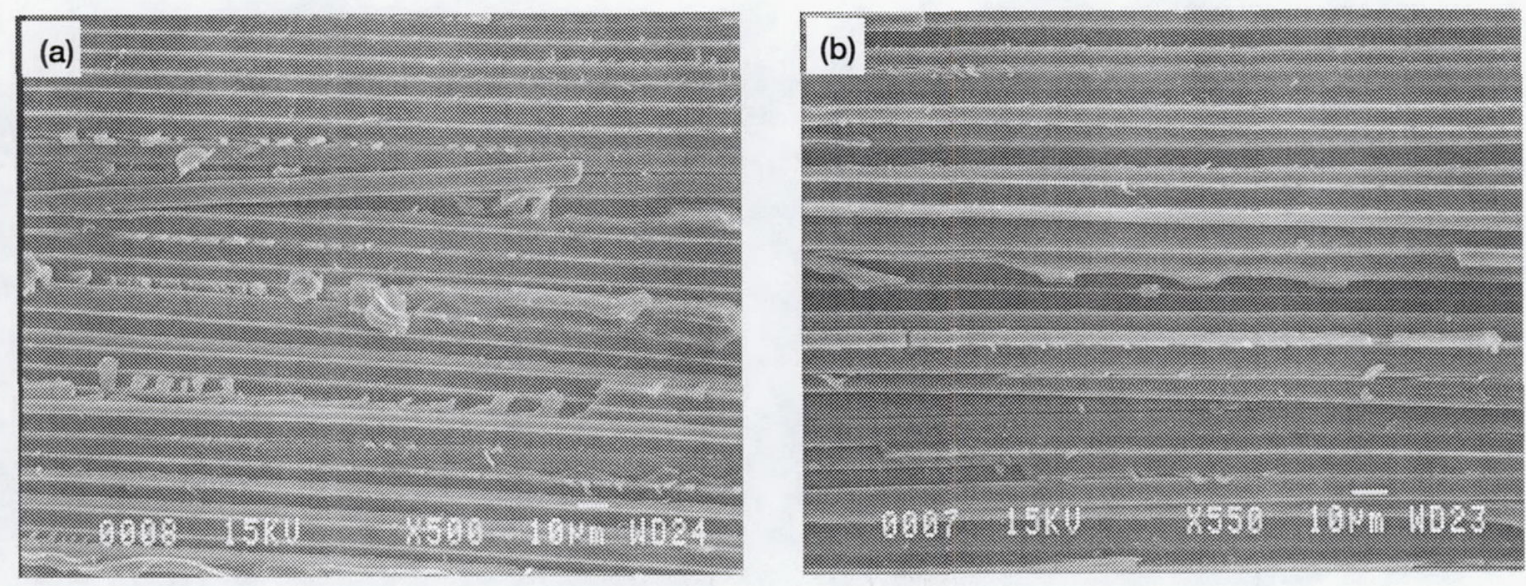

Figure 12.-Fracture surfaces of AU-4 carbon fiber reinforced ENF specimens after completion of tests. (a) No aging. (b) Aged at $316^{\circ} \mathrm{C}$ for $1000 \mathrm{hr}$.
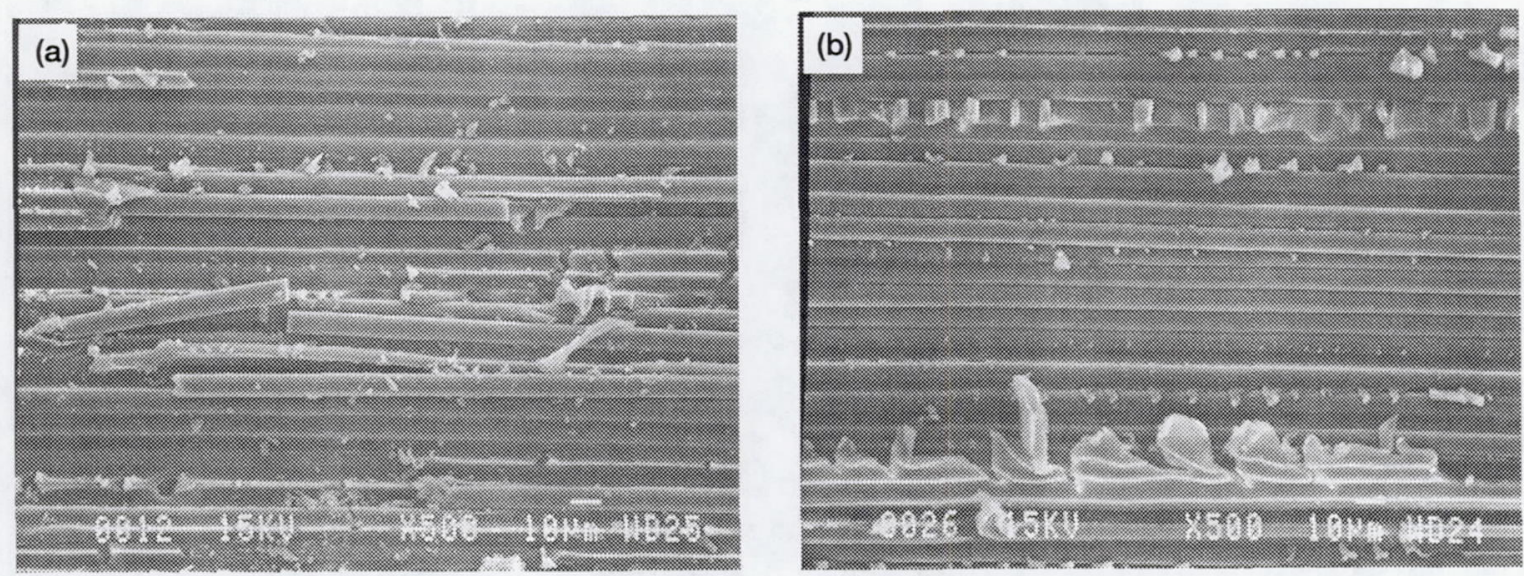

Figure 13.-Fracture surfaces of AS-4 carbon fiber reinforced ENF specimens after completion of tests.

(a) No aging. (b) Aged at $316^{\circ} \mathrm{C}$ for $1000 \mathrm{hr}$.
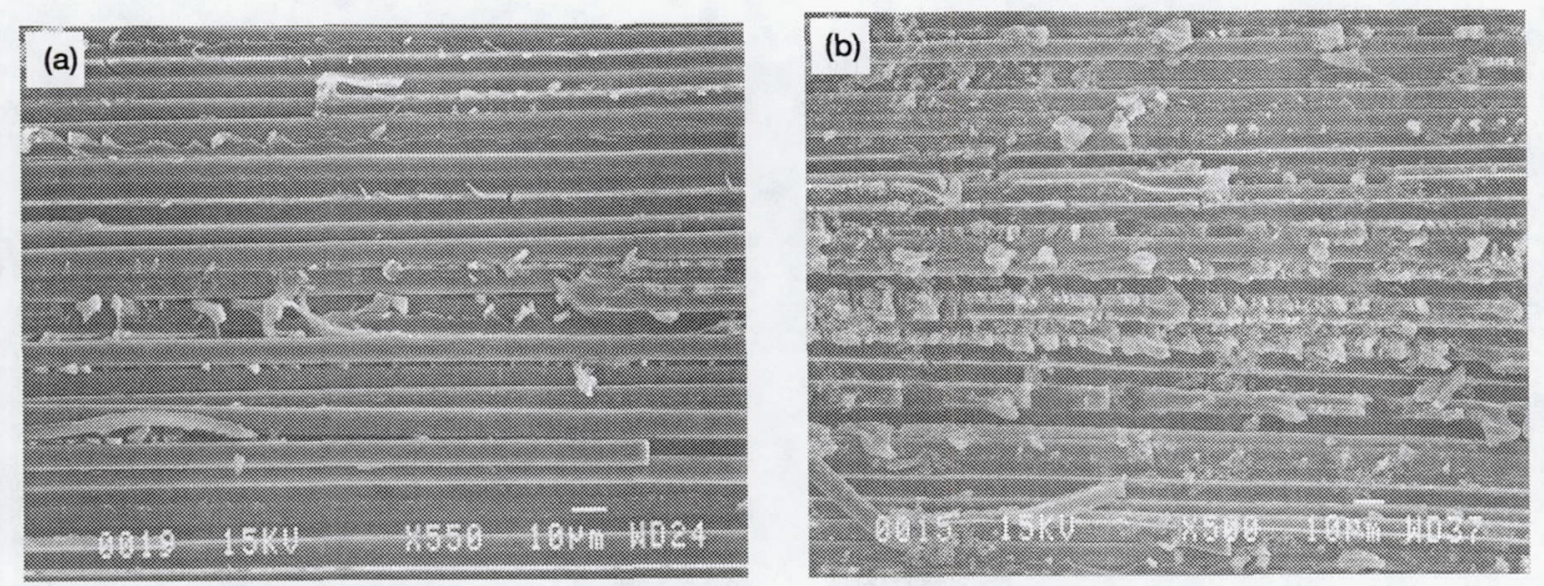

Figure 14.-Fracture surfaces of AS-4G carbon fiber reinforced ENF specimens after completion of tests. (a) No aging. (b) Aged at $316^{\circ} \mathrm{C}$ for $1000 \mathrm{hr}$. 

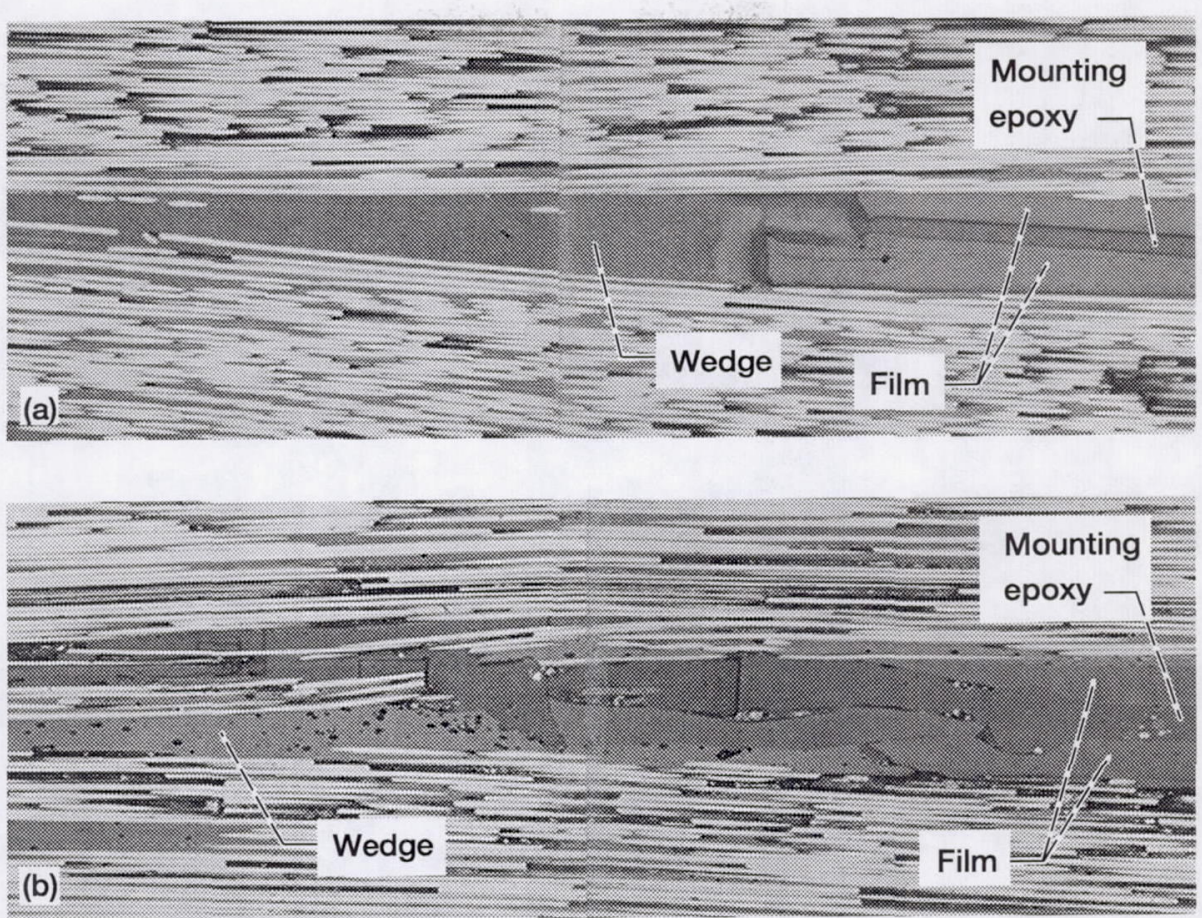

Figure 15.-ENF specimen crack tips after testing 128X. (a) AU-4 fiber, no aging. (b) AU-4 fiber, $1000 \mathrm{hr}$.
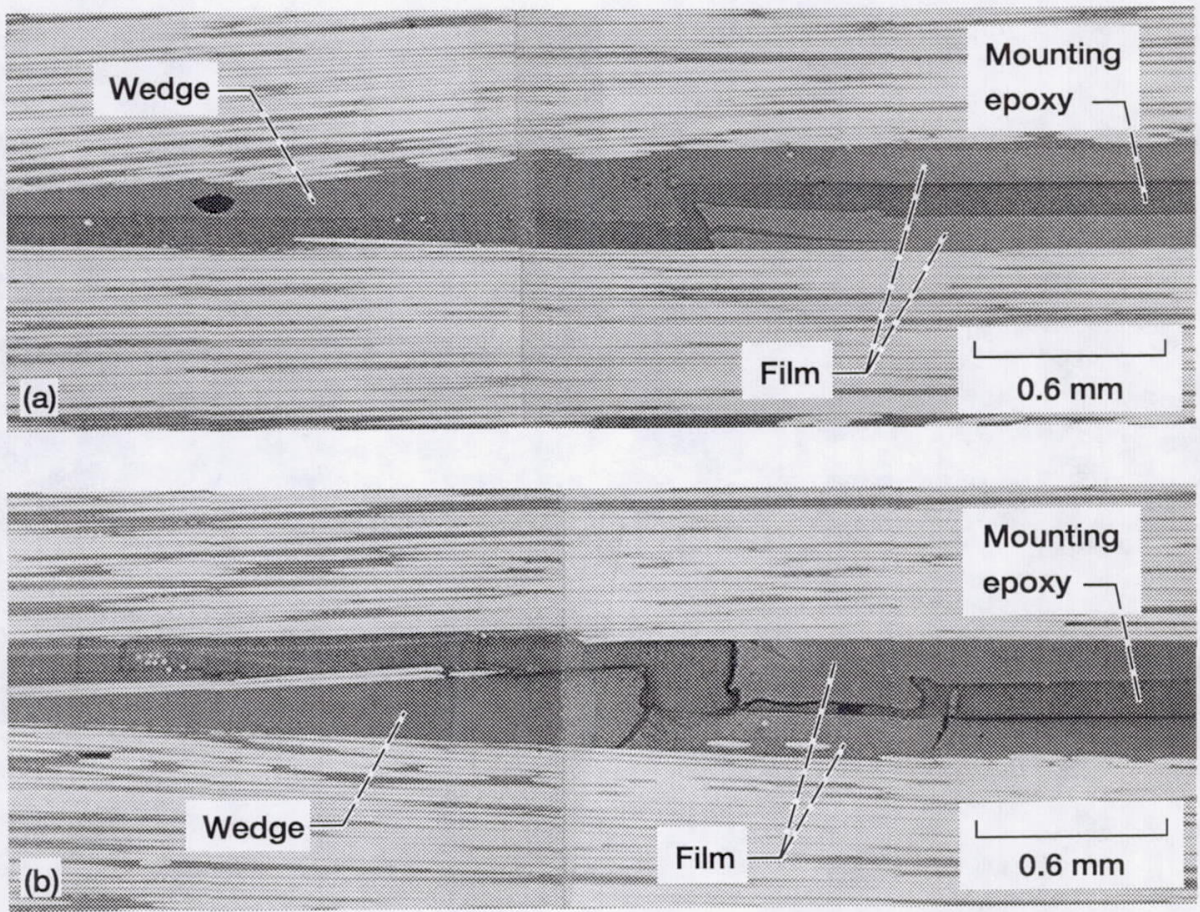

Figure 16.-ENF specimen crack tips after testing 128X. (a) AS-4 fiber, no aging. (b) AS-4 fiber, $1000 \mathrm{hr}$. 

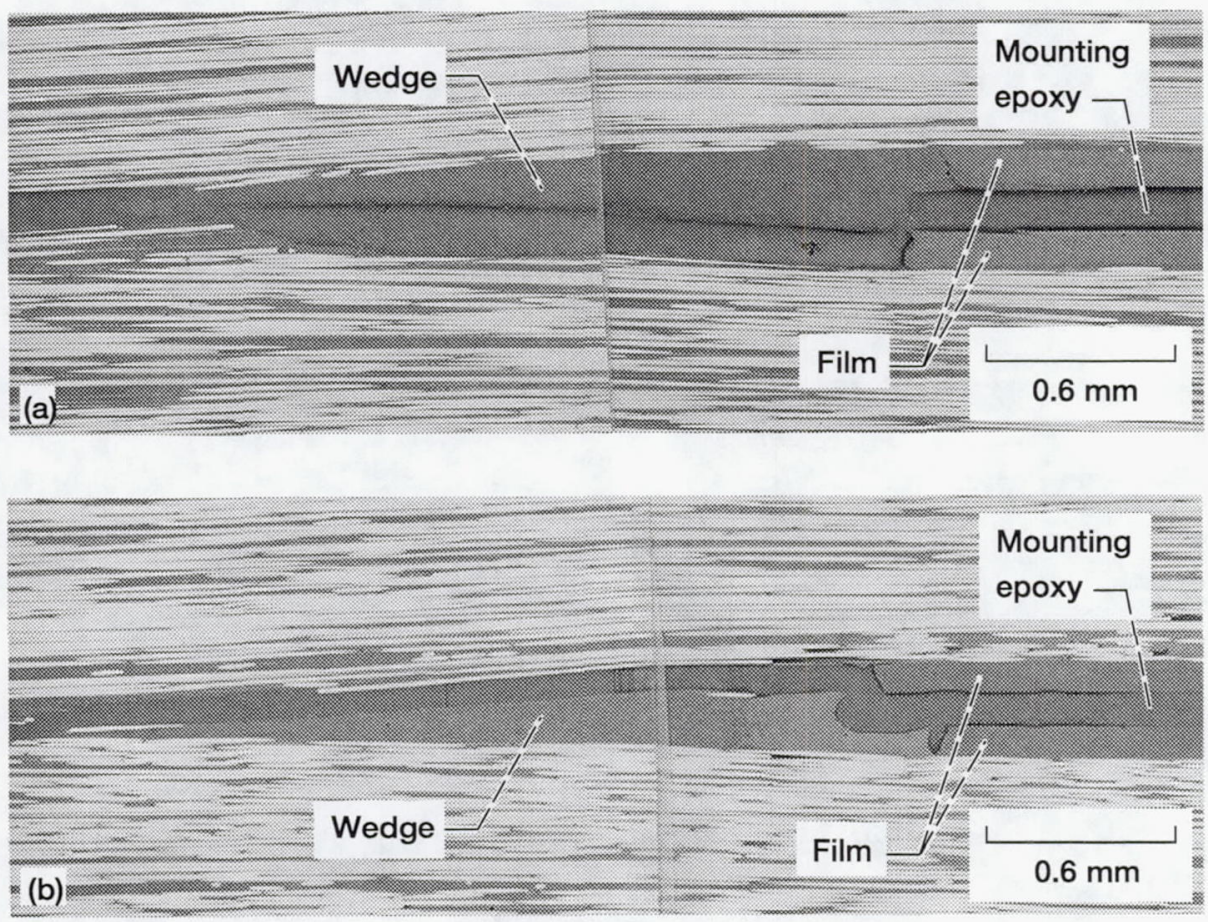

Figure 17.-ENF specimen crack tips after testing 128X. (a) AS-4G fiber, no aging. (b) AS-4G fiber, $1000 \mathrm{hr}$.
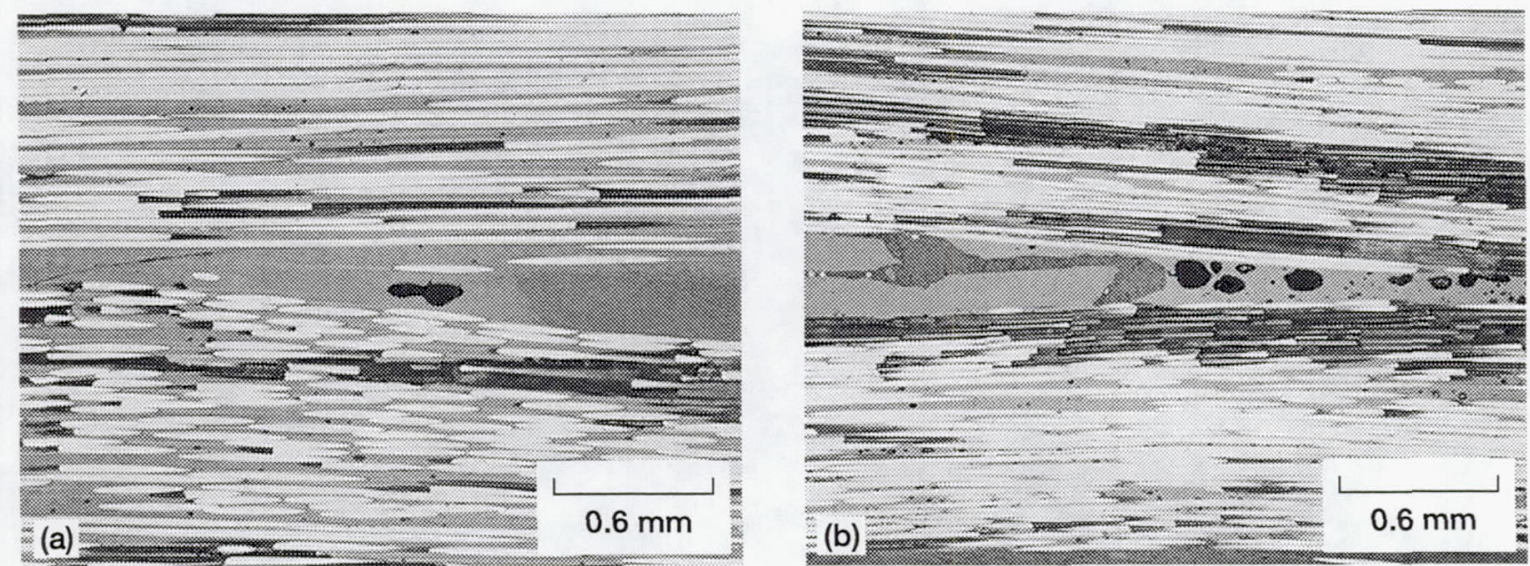

Figure 18.- Untested Mode II specimens of AU-4/PMR-15 composites after aging at $316^{\circ} \mathrm{C}$ for various times. (a) No aging. (b) $1000 \mathrm{hr}$ of aging. 
Public reporting burden for this collection of information is estimated to average 1 hour per response, including the time for reviewing instructions, searching existing data sources, gathering and maintaining the data needed, and completing and reviewing the collection of information. Send comments regarding this burden estimate or any other aspect of this Davis Highway, Suite 1204, Arlington, VA 22202-4302, and to the Office of Management and Budget, Paperwork Reduction Project (0704-0188), Washington, DC 20503.

\begin{tabular}{|l|l|l|l} 
1. AGENCY USE ONLY (Leave blank) & $\begin{array}{r}\text { 2. REPORT DATE } \\
\text { December } 1995\end{array}$ & $\begin{array}{r}\text { 3. REPORT TYPE AND DATES COVERED } \\
\text { Technical Memorandum }\end{array}$ \\
\hline
\end{tabular}

\section{TITLE AND SUBTITLE}

5. FUNDING NUMBERS

The Effects of Fiber Surface Modification and Thermal Aging on Composite

Toughness and Its Measurement

6. AUTHOR(S)

Kenneth J. Bowles, Madhu Madhukar, Demetrios S. Papadopolous, Linda Inghram, and Linda McCorkle

7. PERFORMING ORGANIZATION NAME(S) AND ADDRESS(ES)

8. PERFORMING ORGANIZATION REPORT NUMBER

National Aeronautics and Space Administration

Lewis Research Center

Cleveland, Ohio 44135-3191

WU-505-63-12

9. SPONSORING/MONITORING AGENCY NAME(S) AND ADDRESS(ES)

10. SPONSORING/MONITORING AGENCY REPORT NUMBER

National Aeronautics and Space Administration

Washington, D.C. 20546-0001

NASA TM-106765

11. SUPPLEMENTARY NOTES

Prepared for the 40th International Symposium and Exhibition sponsored by the Society for the Advancement of Material and Process Engineering, Anaheim, California, May 8-11, 1995. Kenneth J. Bowles, NASA Lewis Research Center, Madhu Madhukar, University of Tennessee, 310 Perkins Hall, Knoxville, Tennessee 37996; Demetrios S. Papadopolous, Case Western Reserve University, Cleveland, Ohio 44106; Linda Inghram and Linda McCorkle, Gilcrest Corporation, Cleveland, Ohio 44135. Responsible person, Kenneth J. Bowles, organization code 5150, (216) 433-3197.

12a. DISTRIBUTION/AVAILABILITY STATEMENT

Unclassified -Unlimited

Subject Category 24

13. ABSTRACT (Maximum 200 words)

A detailed experimental study was conducted to establish the structure-property relationships between elevated temperature aging and (1) fiber-matrix bonding, (2) Mode II interlaminar fracture toughness, and (3) failure modes of carbon fiber/PMR-15 composites. The fiber-matrix adhesion was varied by using carbon fibers with different surface treatments. Short beam shear tests were used to quantify the interfacial shear strength afforded by the use of the different fiber surface treatments. The results of the short beam shear tests showed that, for times up to $1000 \mathrm{hr}$, the aging process caused no changes in the bulk of the three composite materials that would degrade the shear properties of the material. Comparisons between the interlaminar shear strengths (ILSS) measured by the short beam shear tests and the $\mathrm{G}_{\text {IIC }}$ test results, as measured by the ENF test, indicated that the differences in the surface treatments significantly affected the fracture properties while the effect of the aging process was probably limited to changes at the starter crack tip. The fracture properties changed due to a shift in the fracture from an interfacial failure to a failure within the matrix when the fiber was changed from AU -4 to AS -4 or AS $-4 \mathrm{G}$. There appears to be an effect of the fiber/matrix bonding on the thermo-oxidative stability of the composites that were tested. The low bonding afforded by the AU-4 fiber resulted in weight losses about twice those experienced by the AS- 4 reinforced composites, the ones with the best TOS.

14. SUBJECT TERMS

Fracture toughness; Composites; PMR-15; Carbon fibers; Thermo-oxidation tests; Interlaminar shear

17. SECURITY CLASSIFICATION OF REPORT Unclassified

18. SECURTYY CLASSIFICATION
OF THIS PAGE
Unclassified

Unclassified
19. SECURITY CLASSIFICATION OF ABSTRACT Unclassified
15. NUMBER OF PAGES 20

16. PRICE CODE

$\mathrm{A} 03$

20. LIMITATION OF ABSTRACT

Standard Form 298 (Rev. 2-89)

Prescribed by ANSI Std. Z39-18 298-102 